\title{
The quadruple helix model of innovation for Industry 4.0
}

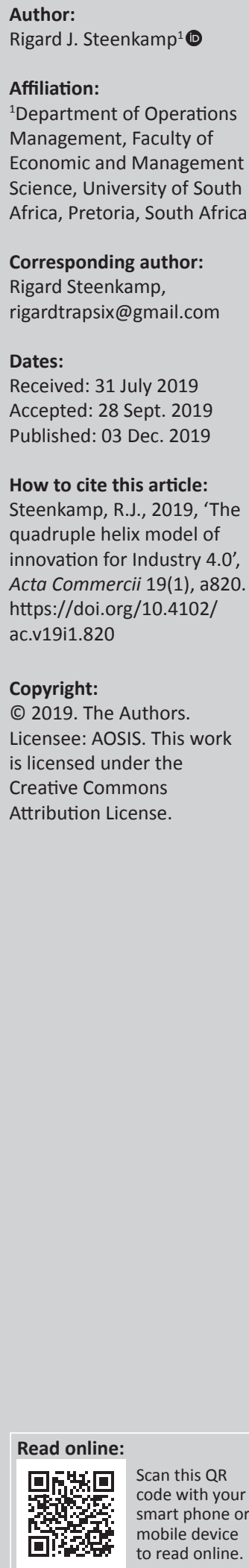

Orientation: The identity of the emerging next industrial revolution is clarified by means of a quadruple helix model. It is revealed how the fourth industrial revolution (FIR), also referred to as Industry 4.0, is underpinned by schemas much more than cyber-physical systems, the internet of things, digitisation and automatic identification technologies such as chips, sensors and internet protocols.

Research purpose: The emotional hype surrounding the FIR and the uncertainty around its identity need clarification. The purpose was to provide balancing perspectives for understanding the primary movements, management theories and sub-revolutions underpinning the emerging FIR.

Motivation for the study: The rationale of the study is to bring more clarity in a collective model of multiple complex innovation concepts.

Research design, approach and method: The study design was qualitative exploration. This implied a sequential exploratory qualitative multi-method process to obtain (1) practical case narrative data (phase A) and (2) theoretical narrative data (phase B).

Main findings: The primary movements underpinning the FIR are (1) triple management theory (TMT), (2) upscaling agility, (3) university-business cooperation (UBC) and triple helix (TH) ecosystem partnerships and (4) epochal society.

Practical/managerial implications: The exponential organisation of the future will require agile leaders who must be geared for change and personal transformation to thrive in a time of endless innovation. This study provides management with valuable insights and clarification of the complexities of innovation into a synthesised quadruple helix model of innovation for the FIR.

Contribution/value-add: The contribution of the study is also generic in terms of its contemporary value, clarifying the FIR identity and to serve as a vantage point of reference for further research.

Keywords: triple helix; triple management theory; innovation; technology; quadruhelix; entrepreneurial university.

\section{Introduction}

This article addresses the emotional hype surrounding the emerging fourth industrial revolution (FIR) and the uncertainty around its identity. The purpose was to provide balancing perspectives for understanding the primary movements, management theories and sub-revolutions underpinning the FIR. The rationale of the study is therefore to bring more clarity in a collective model of multiple complex innovation concepts.

The digitised economy is propelling innovation, and business models must be reinvented for the increasing growth of the virtual world opening up new markets and increasing the range of products, services and competition. Many governments worldwide make technological innovation a social good and economic driver. Since the 1850s, the invention and use of steam power was followed by electrification, synthetic material and mass production in the 1900s. Digital computing and electronic communication were introduced long ago in the sixties and now stand with a potentially emerging FIR with characteristics such as AI (artificial intelligence), new kinds of knowledge management (KM) and small-scale manufacturing. The 2016 study by the World Economic Forum (Caruso 2018:382) predicts an FIR building on the third but characterised by a fusion of technologies that is blurring the lines between the physical, digital and biological spheres. As such, it is not merely a prolongation of the previous revolution. Schwab (2017) confirms the 
current FIR with three realities, namely (1) exponential evolutions (velocity), (2) the integration of technologies (the breadth and depth of what digitisation offers) and (3) holistic system impact across society, industry and countries.

The purpose of this article was inspired by the understandable inflated emotional responses to the FIR, and the collective outcome of this study will bring some balance to the hype. The hype around the astronomical wealth of big data, for example, may not need to be that large in scope, because knowledge is not in the data, but in how well it is utilised. Data is not 'given' in nature, but constructed in previous processes. The promises of government 4.0 , beyond quality (the notion that a state of perfection will eliminate the need for quality management), people taught by machines and more free time because of ultimate productivity must be viewed with care.

The knowledge gap regarding the identity of the FIR and the underlying forces driving it was addressed by considering a conceptual framework or a model of innovation for the phenomenon. Ultimately, this relates to innovators, researchers and technology capability per se. Letaba, Pretorius and Pretorius (2018:172) note the complexities of innovation within sophisticated (and sometimes messy) ecosystems of innovators and researchers. These ecosystems involve dynamic and nonlinear linkages amongst several formal and informal actors. The main models to describe the interplay between these linkages include national systems of innovation (NSI), knowledge triangles and innovation clusters. This article presents these concepts in terms of a quadruple helix model, showing the interplays between the primary streams (movements). Fundamental to all this is the technology capability development and technology roadmapping (TRM) for developing countries.

The ultimate movement (stream) of any industrial revolution is the development and utilisation of technology capability and Simon (1986) was a pioneer in the field of artificial intelligence since 1986. Although the entire global society will be part of the emerging FIR (because of exponential change), many organisations will merely focus on technology capability. This is because many developing countries suffer from underinvestment in research, technology and innovation infrastructures. The problem is exacerbated by the lack of an entrepreneurial and innovation culture, resulting in short-term innovation planning with a focus on basic technological capability development. To improve the situation, Letaba et al. (2018:171) derived an innovation profile from a TRM perspective as a forward-looking tool for all stakeholders, as well as to convert the multiple research outputs into technology platforms. The three main levels of factors influencing innovation programmes are the national innovation landscape (funding, culture, resources and the law), the dominant innovation regime (innovation networks, competition and market demands) and niche innovations (R\&D capability and technology capability) (Letaba et al. 2018:178). These three fundamental factors exist and will remain regardless of the FIR.
Technology capability leads to creative technology management for improvement, maintenance and quality of operations. Although these operations are not necessarily part of a dominant innovation network, they still bring smaller niche innovations to the fore. New developments in technology are natural outcomes of creativity of mankind. For example, normal money sees the lure of crypto and investors going into the cryptocurrency world. Computers are becoming smaller, and with creative companies like Virgin, we should see more weird inventions and more odd jobs. Human creativity will replace normal buildings into intelligent building systems and products. Old machine process technologies with no interfaces (or self-monitoring devices) will be replaced with more intelligent products, processes and machinery. The typical queuing problem for improved customer service was addressed by Aylak, Hendrikse and Du Plessis (2018), when they combined new technology with old simulation principles for cash registers of a giant retail company. A discrete-event simulation model was also constructed using SIEMENS Tecnomatix Plant Simulation software. In addition, Dlamini, Bokoro and Doorsamy (2018) reviewed commonly applied techniques for condition monitoring to improve online and remotely applied monitoring. Digitisation brings about electromagnetic noise replacing audible noise, and Musa and Paul (2018) used a theoretical approach for predicting the attenuation of electromagnetic wave propagation. These examples are not directly related to the FIR; however, they are fundamentally induced by the capabilities of modern technology.

This study will elaborate on the underlying movements towards a conceptual model of innovation for the FIR.

\section{Problem investigated}

The research problem was underlined during conferences with themes related to the FIR, such as the most recent annual Industrial Engineering and Operations Management (IEOM) and European Decision Sciences Institute (EDSI) attended by the researchers in 2018 and 2019. The complexities of innovation as a social good, within sophisticated but somewhat vague ecosystems of innovators and researchers, need categorisation and clarification in the FIR context. The hype of the FIR needs to be balanced by understanding the interplay of underlying sub-revolutions, ecosystems, movements, new management concepts and social forces culminating into exponential innovation associated with the FIR. A newly developed model can address the gap, simplifying these complexities by resolving the different views associated with the FIR identity.

\section{Research methodology}

The study design is based on qualitative exploration, although the researcher supports Morgan's (2018) cautious distinction between qualitative and quantitative research in terms of the 'indistinguishability thesis'. On that account, this investigation draws on a range of theoretical and practical case sources for the exploration of innovation concepts in terms of narrative data, 
which is associated with qualitative research. Cooper and Schindler (2004:723) refer to data collection through observation of physical conditions (infrastructure) and non-behavioural activities. A sequential multi-method exploratory research design was followed to address the problem. The research entailed two phases, namely (1) qualitative observation in terms of personal institutional visits (phase A) and (2) elaboration on the first phase in terms of a literature review, conference proceedings and website information (phase B).

Based on this study design, the first part of the exploration, phase A, entailed experimental observation by means of institutional visits to the study population, namely leading entrepreneurial universities, innovation centres, exhibitions and technology transfer offices (TTOs) on university campuses organised as part of innovation ecosystems. This set of narrative data was related to non-text artefacts (objects of human workmanship as distinguished from natural objects such as designs, photos and sculptures). Personal visits were based on a convenience sample (as recommended by the chair of the university-business cooperation [UBC] conference, the Netherlands) of reputable research institutions located within innovation ecosystems. These institutions are located in Glasgow, Belgium, the Netherlands, Germany and Finland.

Data narratives were thematically grouped from the summative field notes. The basic observation strategy took into account the dimensions of sensory source of experience, the types of observer-participant interaction, the degree of structure and the related type of data. The full-observer category was chosen, and the participants were therefore undisturbed and mostly unaware that they (and the artefacts) were being observed.

The advantages of a low degree of structure during observation and artefact analysis are multiple. They are not expected to respond, but that is not to say that the participants might not react to the presence which happens spontaneously (Plowright 2011:57-58). Another advantage is the less predictability over what data will be collected. This is because the study will be based on open coding of variables.

The researcher could therefore have relatively easy access and more choice over how the data is managed and analysed. Qualitative data is primarily narrative collected at the nominal and ordinal levels (Plowright 2011:122). At the nominal level, the data was labelled to the phenomena under study, and this provided for the classification of information (related to innovation). The next logical step was to reduce data by means of the ordinal levels of data. This involves determining and segregating the priorities by using a ranking order or hierarchy of data. The limitation of this basic observation strategy is in terms of low precision (less detail), but the advantage is the low restriction which is ideal for such an exploratory study.

The data collection phase included access to additional practical cases and reports. These types of secondary data are multiple source publications not available in the public domain (Saunders, Lewis \& Thornhill 2016:307). As noted, the second phase, (B), elaborated on the first phase (A) in terms of synthesis of interpretation, literature, conference proceedings and website information. The rationale of the study was therefore to address the artificial hype surrounding the FIR and to bring more clarity in a collective model of multiple complex innovation concepts.

Ethical considerations were adhered to by way of an ethical clearance certificate received from the researcher's institution (Department of Operations Management, University of South Africa) for this study.

\section{Ethical considerations}

Ethical clearance was provided by the Department of Operations Management ethics review committee at the University of South Africa on 24 August 2018 (reference no. OM-2018-007).

\section{Results}

The results are presented in two sections, namely (1) the narrative data obtained from observation and other practical cases (phase A) and (2) a synthesis of interpretation of phase A with narrative data from secondary sources (phase B).

\section{Results from practical cases (phase A)}

Visits to the sample of innovative universities and institutions provided multiple experimental artefacts related to industrial engineering, technological developments and triple helix (TH) partnerships. The focus was on innovation, and the perspectives obtained were related to technical artefacts such as objects, facilities and institutions that exist by human intervention, contrasted to natural entities. The belowmentioned institutional artefacts observed are organised within ecosystems for innovation:

- A visit to the Maastricht University Brightlands ecosystem revealed their 'CORE' philosophy, namely collaborative open research education. Triple helix (TH) hotspots are created on the Brightlands campuses, and the focus is on specific future industry challenges, such as safety of food, affordable care and cybersecurity.

- The Netherlands is a small but bold nation in terms of innovation and ecosystems. Several visits to typical UBC universities included the Technical University Innovation lab at the Eindhoven University of Technology. This case is unique in that all university activities are related to knowledge transfer and research. Scientific knowledge is translated to small businesses through a specialised TTO.

- The leaders of the Aalto University (Finland) are more solution driven than curriculum focused. The university is renowned for producing more than 3000 doctoral students, brain simulation technology and being ranked very high in the Massachusetts Institute of Technology (MIT) study of the top 200 universities. Design thinking for business innovation is a programme presented by the ESADE business school (Barcelona). The centres of 
excellence include computational nanoscience, inference research, generic intelligent machines and wireless research.

- The 'kennispark' concept was observed in Belgium and the Netherlands. The very creative Kennispark Twente is an innovation campus surrounded by high-tech small-tomedium sized enterprises. The innovation centres and labs are industry-specific, such as for advanced materials, road safety, thermoplastic composites, micro- and nanotechnology, medical imaging and technologies for recycling, wireless sensors, cloud computing and reusing textile. For example, the Apollo Global R\&D centre in Enschede had been established in this region because of the vibrant ecosystem. Medimate, University of Twente, a production location for healthcare solutions and nanoproducts, also forms part of this ecosystem.

- The Innovation Network Science Park (Amsterdam) is established for innovative companies and research organisations who seek partners, valorisation and new ventures.

- Innovation exchange Amsterdam (IXA) (University of Amsterdam) provides support in the entire valorisation process, helping inventors to establish partnerships with organisations. The Technology Centre (TC) develops scientific instruments in the fields of glass, construction, electronics and software.

- Strathclyde in Glasgow, University of the Year 20132014 , is renowned for its centres for innovation focused on applied photonics, forming research and enterprise research with a high spin-off company success rate.

- ASML, Veldhoven (the Netherlands), produces integrated circuits (or chips) populating the modern world of digitisation. Lithography machines produce microchips implying the integration of transistors with the ability to create structures as small as $20 \mathrm{~nm}$.

- The experience at the KU Leuven research-intensive international university in Belgium provided rich narrative data (by observation, reports and articles). The university is central to the Leuven ecosystem, known for the world's leading anti-HIV drug. The TTO revealed how their research valorisation constitutes an important form of societal return. With a long tradition of technology transfer, collaboration with industries and creating spinoff companies, they support high-tech entrepreneurship. The ecosystem consists of several incubators, business centres and science parks similar to those in the Netherlands, such as the Arenberg Science Park and the Haasrode Science Park in Leuven.

The primary summative observational perspective obtained was the $\mathrm{TH}$ principle of engagement by academia, government and business. The entire movement is innovation-induced and not a consequence of the FIR. Innovation for a sound economy is the motivation for the new rules of business. Moreover, the concept of 'ecosystems' evidently places a strong emphasis on social involvement and corporate social responsibility (CSR).
Dondofema and Grobbelaar (2018) used case study research to provide an innovation ecosystem perspective and a value chain perspective on innovation platforms. Table 1 below presents selected cases (from an initial list of over 100) of cooperation between universities and organisations in Europe, prepared for the European Commission by Davey et al. (2011). The types of institutional interaction and achievements in the selected cases, grouped under the categories such as case, method of institutional interaction and impact, are also indicated.

From the observational cases and the additional practical cases obtained in phase A, two primary streams of innovation were evident, namely (1) TH (UBC and TH ecosystems) and (2) society. The results of phase B elaborated on phase A to bring more clarity of multiple complex innovation concepts. Phase A therefore brought the conviction to elaborate on the results with narrative secondary data.

\section{Results from narrative secondary data (phase B)}

As mentioned, the first phase of the explorative study indicated two primary streams of innovation. The researcher's collective experience during phase A provided a conviction and interpretation that these two primary streams are underpinned by unique leadership (agile leadership) and unique management competence (new management theory). A literature study on these produced additional streams of innovation, and the quadruple helix approach was used to organise these streams into the quadruple helix model of innovation.

The systematic approach in phase B therefore comprised an explanation of the quadruple helix concept, organising the primary streams of innovation into a model using the quadruple helix concept, illustrating the quadruple helix model of innovation by means of a figure, and finally describing each of the four streams by means of interpretation, integration and literature.

\section{The quadruple helix concept}

Daemmrich (2017) emphasises the interplay, integration and cross-functional cooperation between innovation systems across scientific disciplines. The $\mathrm{TH}$ concept of the interrelated roles of engagement by academia, government and business as the three $\mathrm{TH}$ actors is fundamental to the quadruple helix concept. The original quadruple helix model adds a fourth component to the TH framework of interaction, namely civil society. The aim was to bridge the gaps between innovation and civil society. This framework claims that, under the triple helix model, the emerging technologies do not always match the demands and needs of society, thus limiting their potential impact. The framework was initially suggested by Carayannis and Campbell (2009) as the 'Quadruple Helix model towards a 21st century fractal innovation ecosystem'. It emphasises the co-existence and co-evolution of different knowledge paradigms. Cavallini et al. (2016) also report on the quadruple helix approach to 
TABLE 1: Selected cases of institutional interaction.

\begin{tabular}{|c|c|}
\hline Case description & Type of interaction \\
\hline $\begin{array}{l}\text { Hermia Ltd with Tampere University of } \\
\text { Technology, University of Tampere and } \\
\text { Tampere University of Applied Sciences }\end{array}$ & $\begin{array}{l}\text { Demola is a Finnish open innovation platform for the creators of next generation } \\
\text { products and services located within the Hermia science park. It provides students and } \\
\text { companies with a collaborative and multidisciplinary innovation environment where } \\
\text { students from three regional universities create novel service and product concepts. The } \\
\text { open innovation approach enhanced into the 'New Factory' platform. }\end{array}$ \\
\hline $\begin{array}{l}\text { Centre for Innovation and Entrepreneur- } \\
\text { ship (CIE) and SMIL University of } \\
\text { Linköping, Sweden }\end{array}$ & $\begin{array}{l}\text { The University of Linköping is involved in networking activities to develop and facilitate } \\
\text { entrepreneurial competencies. The success of these activities is dependent on the SMIL } \\
\text { regional network of companies. }\end{array}$ \\
\hline $\begin{array}{l}\text { Institute of Digital Innovation (IDI), } \\
\text { DigitalCity, Teesside University, United } \\
\text { Kingdom }\end{array}$ & $\begin{array}{l}\text { The institute is one of the two core components of the DigitalCity development in } \\
\text { Teesside, North East England. This initiative is to put the area at the leading edge of } \\
\text { digital technology development. It operates in conjunction with DigitalCity businesses, } \\
\text { located on a separate site in Middlesbrough. It is designed as a centre of excellence to } \\
\text { support graduates and academics. IDI has four core activities, (1) fellowships, (2) } \\
\text { industrial engagement, (3) digital inclusion and (4) cluster promotion. }\end{array}$ \\
\hline $\begin{array}{l}\text { Premio Nazionale Per L'innovazione (PNI) } \\
\text { Cube, Association of the Italian } \\
\text { Incubators and Academic Business Plan, } \\
\text { Italy }\end{array}$ & $\begin{array}{l}\text { PNICube is the association that groups together the academic incubators and the Italian } \\
\text { Academic Business Plan competitions (called Start Cups). Today, it includes } 34 \text { associates } \\
\text { between universities and incubators. It was founded with the purpose of stimulating the } \\
\text { creation of new enterprises. }\end{array}$ \\
\hline $\begin{array}{l}\text { INNPACTO, Spanish Ministry of Science } \\
\text { and Innovation (MICINN), Spain }\end{array}$ & $\begin{array}{l}\text { INNPACTO is a crucial strategic investment of the Spanish Innovation Plan } \\
\text { ('INNOVACCION') under the authority of the Spanish Ministry of Science and Innovation } \\
\text { (MICINN) during the period 2009-2011. }\end{array}$ \\
\hline $\begin{array}{l}\text { Austrian Research Promotion Agency } \\
\text { (FFG), Ministry of Economy, Family and } \\
\text { Youth (BMWFJ), Austria }\end{array}$ & $\begin{array}{l}\text { The Austrian Research Promotion Agency (FFG) is a funding programme. The case } \\
\text { demonstrates how universities and businesses can use this framework to fund } \\
\text { programmes of their own. }\end{array}$ \\
\hline $\begin{array}{l}\text { PROMOTECH, PROMOTECH Living Lab, } \\
\text { France }\end{array}$ & $\begin{array}{l}\text { PROMOTECH is a European community business and innovation centre (EC-BIC). It } \\
\text { provides a process dedicated to the creation of new company ventures. The activity is the } \\
\text { living lab approach for start-up companies. }\end{array}$ \\
\hline $\begin{array}{l}\text { The partnering University approach, } \\
\text { Münster University of Applied Sciences } \\
\text { (MUAS), Germany, North Rhine, } \\
\text { Westphalia }\end{array}$ & $\begin{array}{l}\text { Münster University of Applied Sciences (MUAS), Germany, stands as an example for a } \\
\text { university that has developed a university-wide strategic partnering approach to } \\
\text { cooperate with business. They embraced the concept of long-term, 'early-stage' } \\
\text { partnerships, and collaboration at the highest level have been recognised as best-practice } \\
\text { benchmark. }\end{array}$ \\
\hline
\end{tabular}

Achievements and impacts

Demola highlights the engagement of over 500 students in developing product and service concepts with project partners in over 110 completed projects.

Since SMIL was founded, 16000 entrepreneurs have participated in the different networking activities which included 450 firms and projects.

From April 2008 until the end of March 2011, IDI has awarded 211 fellowships, created 101 businesses and formed 96 business collaboration partners.

In 2010, the programme generated 786 business ideas and 354 business plans, with 2149 participants collectively.

The first call for proposals resulted in a total of $€ 353 \mathrm{~m}$ for $193 \mathrm{R} \& \mathrm{D}$ projects of public-private collaboration.

Of the previous call, 13 of the 14 projects successfully completed the required tasks for the third funding year.

In 2010, 181 entrepreneurs were assisted, and 41 companies were created with 80 new jobs. Under its incubation, there are currently 34 companies providing jobs for 460 employees.

MUAS is the top German university for knowledge exchange and technology transfer (recognised by the German Federal Ministry of Education and Research).

Source: Davey, T., Baaken, T., Deery, M. \& Muros, V.G., 2011, Thirty good practice case studies in university-business cooperation, Science-to-Business Research Centre, Munster University of Applied Sciences, Munster

accelerate the transfer of innovation (and research) results to regional growth of society. The framework therefore emphasises the societal responsibility of universities, a third mission in addition to their role of educating and conducting research (similar to the approach of the European Union for a competitive knowledge-based society). Evidently, civil society has become more prominent, and Caruso (2018:383) identifies four dimensions related to the voice of society, namely customer expectations, product enhancement, collaborative innovation and new organisational designs.

\section{The quadruple helix model of innovation}

The quadruple helix model of innovation is a further development to the $\mathrm{TH}$ and the original quadruple helix model. Leydesdorff (2018:7) provides additional configurations of the $\mathrm{TH}$ model with interactions amongst government, university and industry. One perspective is the evolutionary TH model, described in a similar way by the same triple helix triangle with a focus on innovation by means of policies (replacing government), markets (replacing industry) and sciences (replacing university). This perspective and the characteristics of the digital economy support two new dimensions or streams for innovation in terms of a new kind of management competence (triple management theory [TMT]) and a new kind of leadership (agile and resilient leadership).

Caruso (2018:381) summarises these new management and leadership demands of the digital economy in terms of management of new business models, involving collaboration within TH ecosystems and blurring boundaries between stakeholders. The author relates leading agile operations in terms of resilience, productivity, short lead times, mass customised goods and management of digitised information with high technology investments.

Amongst all the movements, the two additional streams identified (as propositions) from phase B are upscaling agility and TMT. The suggested quadruple helix model for innovation therefore describes:

- epochal society - changes driven by a new intelligent public and an intangible service economy

- upscaling agility - a leadership and value system driving nimbleness, resilience (an essential corollary of agility), flexibility and customisation

- a TH approach to KM and UBC within dynamic ecosystems

- TMT concepts.

The model (see Figure 1) describes and simplifies the four primary streams driving innovation and the emerging FIR for the triple bottom line (3BL).

In terms of the rationale of the study, each of the four streams of innovation will now be described in more detail.

\section{Triple helix ecosystems - Stream 1}

Triple helix: In terms of the FIR, Reischauer (2018) refers to institutionalised innovation systems, such as $\mathrm{TH}$ reshaping 


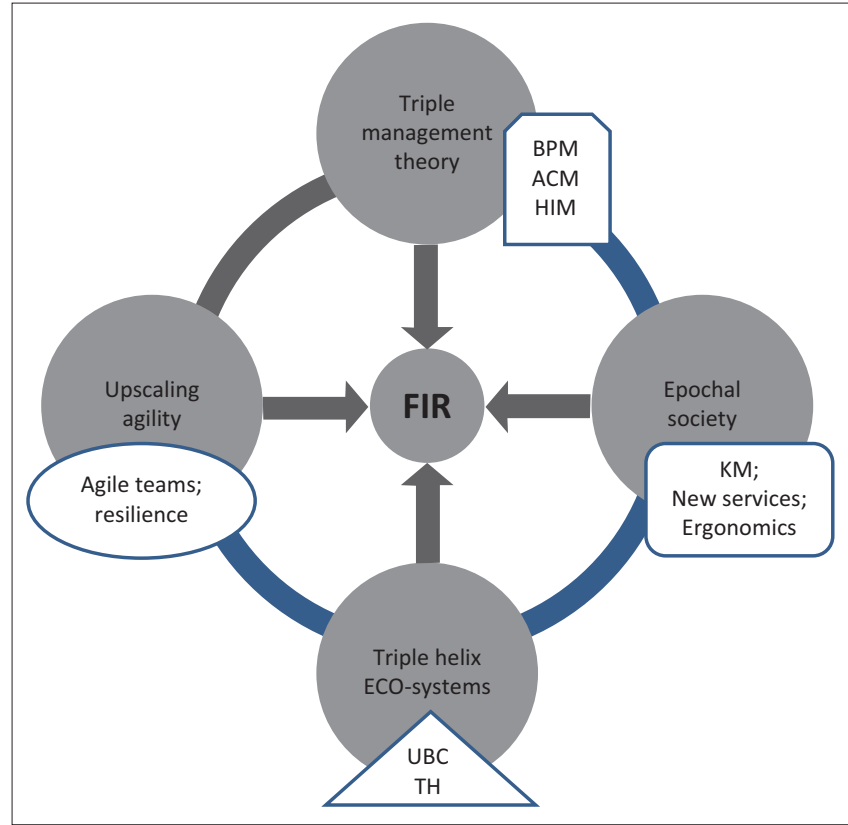

BPM, business process management; ACM, adaptive case management; HIM, human interactive management; FIR, fourth industrial revolution; KM, knowledge management; UBC, university-business cooperation; TH, triple helix.

FIGURE 1: The quadruple helix model of innovation.

manufacturing industries. Leydesdorff (2018) also provides a balanced perspective on the hype surrounding the FIR where a few new metaphors replaced older models. The author argues that innovation is fundamentally associated with the development of capitalism, driven by technological capability.

The UBC principle evolved to the TH concept, referring to knowledge spaces brought about by inter-related roles of engagement by academia, government and business as the three TH actors (Etzkowitz 1994). Leydesdorff (2018) confirms these synergies as knowledge-based innovation systems in terms of the TH. The concept is widely promoted through the Triple Helix Association (http: / / www.triplehelixassociation. org), originated at Stanford University under the leadership of Professor Henry Etzkowitz. The MIT is one of the most highly rated universities in the world and a benchmark for triple helix consultation, helping universities to cooperate with industry and government. The TH model of innovation highlights the multidisciplinary foundation of innovation as a model for analysing innovation in a knowledge-based economy. Organisational effectiveness will increase with the blurring borderlines of UBC and TH partnerships, moving beyond neoliberal capitalism that has underpinned globalisation since the eighties (Holbeche 2018:303, 304).

The TH vision challenged traditional ways of how business, politics and academia innovate. It urged them to cross the borders of the sphere of society (Etzkowitz \& Viale 2010). The multiple compelling cases that show why businesses should collaborate with universities include an increase in patent applications and $\mathrm{PhD}$ students for universities. The Australian Bureau of Statistics confirms that around 16000 Australian businesses have formal partnerships with universities. That amounts to an average of 410 industry partnerships at each of the 39 universities (Universities Australia n.d.). Furthermore, Hofste-Kuipers (2016) from the University of Twente (UT) indicates how UT became the top institute in the valorisation ranking of Dutch universities.

The intrapreneurship ecology: Fundamental to university engagement is a culture of academic intrapreneurship and entrepreneurship. Dovey and Rembach (2015) acknowledge innovative outcomes because of intrapreneurship within the academy.Hecker (2017) argues that in-houseintrapreneurship, such as non-technological innovations, is not always formal but is the result of entrepreneurial employee behaviour that breaks with customary business practice. Sam and Van der Sijde (2014), who reviewed different higher education models in the debate of academic capitalism, indicate that most models at least accommodate intrapreneurship as a social good. It is imperative that the antecedents to such a fertile organisational ecology of innovation be developed. Douglas and Fitzsimmons (2013) note that intrapreneurs in any organisation are usually highly action-oriented and comfortable with taking initiative, also within the boundaries of an academic organisation. This mind-shift is fundamental for the transformation of universities into commercially engaged institutions. Kafile (2018:188) provides a framework of intrapreneurial activities for corporate entrepreneurship with the potential of bringing academic institutions and the industry into closer alignment.

The entrepreneurial university revolution: The conservative slowness of public higher education institutions will not suffice in a turbulent world with shifting tectonic plates and growing anti-globalisation. The universities of the future will need to adapt to an intelligent society and public awareness where elite talent is able to command its price and where there are more markets in more sectors. This revolution (also referred to as university 4.0) and integral ingredient of industry (III) is at the heart of innovation. Highly ranked universities are mostly entrepreneurial, open for engagement and involved in partnerships. Stanford, MIT, Princeton, Yale and Harvard serve as examples. In their investigation of espoused values, Loi and Chiara Di Guardo (2015) refer to the third mission of universities as 'an invisible revolution'. This is, by interpretation, a new kind of KM with established industry-science links (ISLs) and TTOs actively engaging in different configurations of UBC. Van Looy et al. (2004) report on a study indicating how scientific performance and entrepreneurial activity amongst academia promote research outputs. Van Looy et al. (2004:438-439) state that this interaction is becoming more significant, pointing towards cumulative advantages in terms of the Matthew effect.

\section{Epochal society - Stream 2}

In 1979, the futurist Alvin Toffler popularised the concept of a new information era underpinned by key ideas, such as the end of mass production, customisation of products and services, decentralisation, interactivity and hyper-flexible 
employment. In this context, Caruso (2018:379-390) envisions a society with an improved work-life balance within a knowledge-based economy (KBE), a virtual society and a network society.

Society has entered a modern social-technical world seeing mega changes, mega trends, megacities and mega technology. This includes both comfortable improvements and uncomfortable mega disruptions, integral towards an intangible economy where businesses and technology merge. Ordinary products will become connected and smart, whilst industry-specific revolutions will take place in higher education, health care, green environments, food security and other predominant service industries.

The knowledge society: Carayannis and Campbell (2009) emphasise society as part of the emerging fractal knowledge and innovation ecosystem, well configured for the knowledge economy. KM has evolved over decades, whilst society has become more educated, self-empowered and knowledgeable about the broad innovation economy. Society has gained an intelligence born from the new knowledge society, demanding answers and asking more questions about privacy, safety and wellness. Society also demands more respect, because of the extreme realities of corporate scandals and social disasters on the one hand and the fastchanging technological world on the other. Society has thus become more intelligent, yet also more gullible for the waves of the so-called social good things and the inchoate transformation of how goods and services are produced. This stream is crucial in terms of the voice of the customer and the dangers of the internet of 'things' (not people). It will need to resist the power of intelligent machine productivity and false utopian promises associated with the FIR.

Social respect also relates to social-technical ergonomics, health, wellness, safety and a green environment. Moreover, 'smart factories' with machine-to-machine communication through unique cyber-physical systems and the dimensions of the FIR are not merely accepted. Society has therefore become the informal students of the knowledge society and a prominent actor of the quadruple helix model.

The service economy: As society demanded more services, the service economy of the world has become the largest contributor to the global gross domestic product (GDP). The rise of the service sector over the last decades can be attributed to the natural evolution of economies from manufacturing, agriculture and then to services. In the early seventies, Braverman (1974) introduced the concept of a scientifictechnical revolution, and the key innovation included both products and services, which is not only found in banking, health care, education, electronics, automatic machinery, aeronautics, chemistry or atomic physics, but also in the transformation of science itself into capital.

With the expansion of service industries, Adendorff and De Wit (1999:318-324) note that the production management discipline was named 'operations management' to encompass services. The demands of society have led to various types of service operations systems (based on client contact), which include pure service systems (the client is constantly part of the service process), mixed service systems and professional services. The service package usually consists of a combination of support facilities, support goods, explicit versus implicit advantages, core versus peripheral services and tangible and intangible components. Service demands with a strong personal, tailor-made, human element may increase because of many impersonal electronic services, such as data. The knowledge society will therefore also demand more services from higher education institutions in terms of types of offerings and modes of service delivery. Caruso (2018) refers to the information technologies of the future giving hope concerning the ongoing progress and upgrading of skills with unique explicit and implicit vocational benefits taught by means of modern education.

Social ergonomics: The overwhelming focus on aesthetics of things at the cost of the well-being of people has led to social ergonomics emphasising human well-being at large. The social ergonomics philosophy promotes technology that fits people by challenging the status quo. Social-technical ergonomics has a new focus on social respect based on the optimisation of anthropometric data, digital human models (DHMs), computer-aided tools, cybernetic ergonomics and ergonomic-friendly machines. This approach will enforce multi-faceted ergonomics based on human factors (Karwowski 2006), anthropometry, biomechanics, social psychology, applied psychology and environmental physics. In this regard, the Cornell University Human Factors and Ergonomics Research Group (CHFERG) (CUErgo n.d.) plays a leading role with concepts, such as 'ergotecture' and 'ecotecture'. Furthermore, the body of knowledge of the International Ergonomic Association (IEA) categorises the science into physical ergonomics, cognitive ergonomics and organisational ergonomics (optimising the sociotechnical system).

Epochal social changes: Besides the new knowledge society expanding service industries and social-technical ergonomics, it is important to elaborate on the implications of the cyber society. Caruso (2018) notes the advantages of society in terms of digital capitalism, balancing small and large companies, blurring boundaries between entities, the growth in autonomy, freedom and creativity. Yet, this utopia of the operations management dream (productivity), short lead times and freedom from the burden of hard manual work may not be for all. Some may choose to follow a conservative approach of minimalism and less risk with knowledge workers running the processes as technological slaves. The negative consequences of the digital revolution also relate to job security and estimates that before 2020, 2.1 million new jobs will be created at the cost of 5 million jobs (Caruso 2018:384). However, the ambivalences and dichotomies are related to socialisation of the production process, cooperative exchanges, the new social contents of work and collective participation in decision-making. 


\section{Upscaling agility - Stream 3}

The global economy demands leaders to perform in terms of the 3BL as today's tumultuous markets need fast-moving adaptive organisations with agility, resilience and mass customisation. Innovation and the selection of technologies appropriate for mass customisation (MC) relate to agility (Dube \& Mbohwa 2018). With innovation inherently part of the DNA of the exponential organisation (this refers to the modern organisation that grows above average rate, uses fewer resources and uses new technologies such as digitisation), its personality and culture will be agile. Leaders will model the way for the creation of more effective organic organisations requiring a radical shift in conventional leadership because agility and resilience (an essential corollary of agility) must have strong foundations. Trust is part of this currency, as being agile is to be able to work as open networks rather than in closed hierarchy. Holbeche (2018) defines agility as the capacity to respond, adapt quickly and thrive in a changing environment captured by key components, such as future focus, customer collaboration, iteration and experimentation.

Holbeche (2018:304, 306) highlights the three primary characteristics of agile organisations:

- an organisational culture and structure that facilitates change

- willing and able staff

- a continuous learning mind-set in the mainstream business.

Agility is therefore a combination of extraordinary characteristics of operations performance objectives, such as speed, cost-effectiveness, flexibility and quality. Organisational effectiveness is a somewhat contested science but will need reimaging because of the demands and opportunities of agility.

If innovation is part of the DNA of exponential organisations, then agile teams are ideal as creative vehicles to experiment, take judicious risks and be accountable. To deploy agile teams is a challenging one, because they can easily find themselves bottlenecked by slow-moving bureaucracies. Some companies were designed agile from the start, whilst others like Amazon are making the transition to become agile (Rigby, Sutherland \& Noble 2018). It is good practice to have three general agile team categories, namely customer experience teams, business process teams and technology system teams. Even the most agile enterprises like Google, Netflix, Bosch, Saab, Tesla and SpaceX operate within a mix of agile teams and traditional structures. SAP rolled out to more than $80 \%$ of its development organisations as agile, creating more than 2000 teams (Rigby et al. 2018). This stream clearly complements $\mathrm{TH}$ and the needs of society.

\section{Triple management theories - Stream 4}

The arrival of new markets, velocity, scope, exponential pace and systems have an impact on exponential organisation striving for the 3BL in terms of unique management approaches. This includes TH partnerships, UBC configurations, resilient mechanisms, interactive mechanisms and mechanisms for interoperability. Management will learn faster (knowledge on the go) and will use new terms such as net shape manufacturing (with three-dimensional printing) and new meanings for old concepts such as intelligent systems engineering (ISE). All these 'triple' concepts are in line with the TMT concept (and the three agile team categories of stream 3 ) supporting process intelligence (inherent to operations management) with principles for operational flexibility, technological flexibility, workflow orchestration, and system interoperability.

In search of perfection, no management system is complete, and principles of TMT can be of great benefit to fill the weak spots. TMT ensures that information, processes and technology become organic and therefore flexible enough to allow interoperability between them by creating a suitable information technology (IT) infrastructure. To cope with radical change in the digital revolution, Raheem (2018) uses a combination of process-centric and human-centric management theories to be in pace with technology flexibility. His work shows how interoperability and technological flexibility can be supported at management level, whilst the workflow effort can be estimated more accurately.

TMT is a combination of BPM (business process management), ACM (adaptive case management) and HIM (human interactive management) to support change and interoperability resulting from collaboration between multiple organisations. Raheem (2018:11, 12) notes that BPM has a wider scope as work-flow management (WFM), to include process automation, process analysis and operations management. Human participation in $\mathrm{BPM}$ is important to achieve social interaction, utilising social software and its principles. ACM, on the other hand, is emphasising a case management process by maintaining case examples on record to support future decision-making, whereas HIM provides simple and effective ways by which people interact with resources such as process technologies, machine modules and people. A proper HIM system can make a huge difference to avert delay and interrupt rudimentary norms.

Business process management (BPM) has obtained a new meaning because of the drive for high performance in the digital age. Kirchmer (2018) refers to a global study indicating that $75 \%$ of organisations have started their digital journeys, but only $1 \%$ have their business processes sufficiently under control to realise the full potential of their digital initiatives. Kirchmer (2018:38-39) also refers to the upshift leading to BPM 4.0 leveraging the power of the internet to enhance process management. Process impact assessments in digital form must be linked to the value drivers of organisations to identify the ideal improvement approaches. Process intelligence will then lead to process governance as a value network across the traditional organisation. TMT is therefore a collective term in terms of modern management sciences underpinning innovation for the FIR.

\section{Discussion}

The emotional hype surrounding the FIR includes a view that the new industrial revolution, that is strategically 
fabricated by revisionists to be an indispensable world economic saving movement, can either be regarded as outright obstinate nonsense or treated with conservative cautiousness. It can do no harm to consider both views, but the inextricable fact is the changing world economy. It does not necessarily ameliorate for the good, although potential misconceptions may produce surprising plutocracy with superlative outcomes; it may also see platitudinous products and services that may even be malignant.

Adams and Mpofu (2018) reviewed the FIR in terms of emotional contradictions, and also investigated game changing cases, such as Exxon Mobil, Procter and Gamble and Tata Motors. They consequently developed a tool for companies to assess their status in terms of the FIR. Some companies will remain neutral to the movement; others may believe it to be the norm, whilst some may even be integral to the FIR without knowing it. Daemmrich (2017:257, 261, 262) has an entrepreneurial view of lower barriers between inventors and markets because costs for small companies for niche markets will drop. Artificial intelligence (AI) and robotics will play a far more active role for new avenues of growth and new jobs. The swelling data deluge is a movement on its own, and there is no doubt that with big data sets we can do things that were previously impossible. The number of zettabytes of data produced in the world may even grow to 40 zettabytes during the next few years. The functionalities for data storage and information exchange will be commendably positive, and products will have passive data storage as well as storage for autonomous information exchange.

Other balancing perspectives are the 'FIR toolbox' representing both old and new technologies. Sensors, for example, are nothing new but the integration of sensors is, and sensor readings are now processed by the product. Besides data storage and exchange, the toolbox will dramatically improve in terms of monitoring (detection of failures). Touch tracking software will pick up and track an unlimited number of fingers, hands and objects, providing an explosion of new data. With reference to the quadruple helix model, the FIR toolbox (big data, digitisation and others) will be fundamental for TMT (stream 4 of the quadruple helix model). Ultimately, the study brought more clarity of the FIR identity in a collective model of four streams representing multiple complex innovation concepts.

\section{Key findings}

The key findings of the exploration of the forces of innovation provided a summative and balanced perspective on the emotional hype surrounding the FIR (and its 'toolbox') as nonnormative. The ultimate movement (and priority) of any industrial revolution is the development and utilisation of technology capability. In terms of digitisation, as high as $75 \%$ of organisations have started their digital journeys; however, only $1 \%$ has their business processes sufficiently under control to know the full potential of their digital initiatives. This (and the entire article) shows that AI is what it says: non-authentic intelligence. Yet, this article provided important innovation principles and concepts for the modern exponential organisation in terms of the interplay of underlying subrevolutions suggested by the quadruple helix model culminating into the emerging next industrial revolution.

\section{Strengths and limitations}

Although the sample of the best known innovation institutions were part of the study and contributed to closing the knowledge gap, the proposed quadruple helix model of innovation for the FIR must be regarded as iterative and not cast in stone because of the reality of the fast-changing society.

\section{Implications or recommendations}

This study could bring balance to the hype (uncertainties and fear) surrounding the FIR and provide more clarity on its identity. It is recommended that managements utilise the model as a frame of reference, whilst further studies should test and improve the quadruple helix model of innovation.

\section{Conclusion}

The research problem was addressed by an investigation to explain the interplay between underlying sub-revolutions, movements and new management concepts culminating into the emerging next industrial revolution. The identity of the FIR was clarified with a quadruple helix model showing how the FIR is underpinned by much more than AI, cyber-physical systems, the internet of things and digitisation. The primary movements relate to new management theory, a strong focus on agile leadership and the dimensions of broader society with its ecosystems. The four streams of the model were grouped and described as:

- TMT

- upscaling agility

- TH partnerships and UBC and

- epochal society.

These movements are not FIR-induced but innovationdriven.

\section{Acknowledgements Competing interests}

The author declares that no competing interests exist.

\section{Authors' contributions}

I declare that I am the sole author of this research article.

\section{Funding information}

This research received no specific grant from any funding agency in the public, commercial or not-for-profit sector.

\section{Data availability statement}

Data sharing is not applicable to this article as no new data were created or analysed in this study. 


\section{Disclaimer}

The views and opinions expressed in this article are those of the author and do not necessarily reflect the official policy or position of any affiliated agency of the author.

\section{References}

Adams, D.Q. \& Mpofu, K.M., 2018, 'What has Industry 4.0 got to do with us? A review of the literature', Proceedings of the International Conference on Industria Engineering and Operations Management, October 29-November 01, 2018, IEOM Society International, Pretoria.

Adendorff, S.A. \& De Wit, P.W.C., 1999, Production and operations management. A South African perspective, 2nd edn., Oxford University Press, Cape Town.

Aylak, B.L., Hendrikse, H.C.N. \& Du Plessis, A., 2018, 'Cash register queue simulation scenarios for a giant retail company', Proceedings of the International Conference
on Industrial Engineering and Operations Management, IEOM Society In Industrial Engineering and Operations Mana.

Braverman, H., 1974, Labor and monopoly capital. The degradation of work in the twentieth century, Monthly Review Press, New York.

Carayannis, E.G. \& Campbell, D.F.J., 2009, 'Mode 3 and quadruple helix model towards a 21st century fractal innovation ecosystem" International Journal of Technology Management 46(3/4), 201. https://doi.org/10.1504/IJTM.2009.023374

Caruso, L., 2018, 'Digital innovation and the fourth industrial revolution: Epochal socia changes?', Al \& Society 33(3), 379-392. https://doi.org/10.1007/s00146-017 0736-1

Cavallini, S., Soldi, R., Friedl, J. \& Volpe, M., 2016, Using the quadruple helix approach to accelerate the transfer of research and innovation results to regional growth European Union Committee of the Regions, Belgium.

CUErgo, n.d., Ergonomics: Human-Centered Design, viewed n.d., from http://www. ergo.human.cornell.edu

ResearchGate. Catalogue number: QG-02-16-576-EN-N ISBN: 978-92-895-0890-2. https://doi.org/10.2863/408040

Cooper, D.R. \& Schindler, P.S., 2004, Business research methods, 12th edn., McGraw Hill, New York.

Daemmrich, A., 2017, 'Invention, innovation systems, and the fourth industria revolution', Technology \& Innovation 18(4), 257-265. https://doi.org/10.21300/ 18.4.2017.257

Davey, T., Baaken, T., Deery, M. \& Muros, V.G., 2011, Thirty good practice case studies in university-business cooperation, Science-to-Business Research Centre, Munste University of Applied Sciences, Munster.

Dlamini, A., Bokoro, P. \& Doorsamy, W., 2018, 'A review of metal oxide surge arrester models for remote monitoring application', Proceedings of the International Conference on Industrial Engineering and Operations Management, October 29November 01, 2018, IEOM Society International, Pretoria.

Dondofema, R.A. \& Grobbelaar, S., 2018, 'A methodology for case study research to analyse innovation platforms in the South African healthcare sector', Proceedings of Management, October 29-November 1, 2018, IEOM Society International, Pretoria.

Douglas, E.J. \& Fitzsimmons, J.R., 2013, 'Intrapreneurial intentions versus entrepreneurial intentions: Distinct constructs with different antecedents', Small Business Economy (Springer Business) 41(1), 115. https://doi.org/10.1007/s11187-012-9419-y

Dovey, K. \& Remback, M., 2015, 'Invisible practices, innovative outcomes: Intrapreneurship within the academy', Action Learning: Research and Practice 12(3), 276. https://doi.org/10.1080/14767333.2015.1074885

Dube, P. \& Mbohwa, C., 2018, 'A framework for evaluating and selecting technologies appropriate for mass customisation', Proceedings of the International Conference on Industrial Engineering and Operations Management, October 29-Novembe 01, 2018, IEOM Society International, Pretoria.

Etzkowitz, H., 1994, 'Academic-industry relations: A sociological paradigm fo economic development', in L. Leydesdorff \& P. Van den Besselaar (eds.), Evolutionary economics and chaos theory: New directions in technology studies, pp. 139-151, Pinter, London.
Etzkowitz, H. \& Viale, R., 2010, 'Polyvalent knowledge and the entrepreneurial university: A third academic revolution?', Critical Sociology 3(4), 595-609.

Hecker, A., 2017, 'The intrapreneurial nature of organizational innovation: Toward a new process model', International Journal of Innovation 5(3), 375-398. https:// doi.org/10.5585/ijji.v5i3.208

Hofste-Kuipers, M., 2016, 'How UT became number one in the valorisation ranking of Dutch universities', paper presented at the University Industry Interaction Conference, Amsterdam, 1-3rd June.

Holbeche, L.S., 2018, 'Organisational effectiveness and agility', Journal of Organizational Effectiveness; People and Performance 5(4), 302-313. https://doi. org/10.1108/JOEPP-07-2018-0044

Kafile, M., 2018, 'A framework of intrapreneurship for corporate entrepreneurship: A case study of organisational development', Educor Multidisciplinary Journal 1(1) 171-191.

Karwowski, W., 2006, 'The discipline of ergonomics and human factors', in G. Salvendy (ed.), Handbook of human factors and ergonomics, 3rd edn., pp. 3-31, John Wiley \& Sons, Hoboken, NJ.

Kirchmer, M., 2018, 'Enabling high performance in the digital age', Industrial and Systems Engineering magazine, Institute of Industrial Engineers, viewed 29 July 2019, from www.iise.org/ISEmagazine.

Letaba, T.P., Pretorius, M.W. \& Pretorius, L., 2018, 'Innovation profile from the perspective of technology roadmapping practitioners in South Africa', South African Journal of Industrial Engineering 29(4), 171-183. https://doi. org/10.7166/29-4-1919

Leydesdorff, L.J., 2018, 'Synergy in knowledge-based innovation systems at national and regional levels: The triple-helix model and the fourth industrial revolution', Journal of Open Innovation: Technology, Market and Complexity 4(16), 1-13. https://doi.org/10.3390/joitmc4020016

Loi, M. \& Chiara Di Guardo, M., 2015, 'The third mission of universities: An investigation of the espoused values', Science and Public Policy 42(6), 855-870. https://doi.org/10.1093/scipol/scv012

Morgan, D.L., 2018, 'Living within blurry boundaries: The value of distinguishing between qualitative and quantitative research', Journal of Mixed Methods Research 12(3), 268-279. https://doi.org/10.1177/1558688916686433

Musa, A. \& Paul, B.S., 2018, 'Electromagnetic wave attenuation and phase rotation by charged dust particles', Proceedings of the International Conference on Industrial Engineering and Operations Management, October 29-November 01,2018, Engineering and Operations Managen
IEOM Society International, Pretoria.

Plowright, P., 2011, Using mixed methods - Frameworks for an integrated methodology, Sage, London.

Raheem, R.O., 2018, 'Triple management theory and agility, technology interoperability and flexibility challenges in a specified domain', The IUP Journal of Knowledge Management 16(2), 7-48.

Reischauer, G., 2018, 'Industry 4.0 as policy-driven discourse to institutionalize innovation systems in manufacturing', Technological Forecasting \& Social Change 132(C), 26-33. https://doi.org/10.1016/j.techfore.2018.02.012

Rigby, D.K., Sutherland, J. \& Noble, A., 2018, 'Agile at scale', Harvard Business Review May-June Issue, 88-96.

Sam, C. \& Van der Sijde, P., 2014, 'Understanding the concept of the entrepreneurial university from the perspective of higher education models', Higher Education 68(6), 891-908. https://doi.org/10.1007/s10734-014-9750-0

Saunders, M., Lewis, P. \& Thornhill, A., 2016, Research methods for business students, 7th edn., Pearson Education, Edinburgh Gate, Essex.

Schwab, K., 2017, The fourth industrial revolution, p. 3, Portfolio Penguin.

Simon, H.A., 1986, 'The information processing explanation of Gestalt phenomena' Computers in Human Behavior 2(4), 241-255. https://doi.org/10.1016/07475632(86)90006-3

Universities Australia, n.d., Clever Collaborations: The strong business case for partnering with universities, viewed 28 February 2018, from https://www. universitiesaustralia.edu.au/publication/clever-collaborations/.

Van Looy, B., Ranga, M., Callaert, J., Debackere, K. \& Zimmerman, E., 2004, 'Combining entrepreneurial and scientific performance in academia towards a compounded and reciprocal Matthew-effect', Research Policy 33(3), 425. https://doi. org/10.1016/j.respol.2003.09.004 